\section{Neonatal Chikungunya Infection}

\section{Abstract}

Chikungunya virus is a member of the genus Alphavirus, in the family Togaviridae. Infected mosquitoes can spread the virus to other humans when they bite. The symptoms include fever, petechial or maculopapular rash and arthralgia or arthritis affecting multiple joints mainly in adults. The illness is usually self-limiting and will resolve with time. The time of greatest risk of transmission from mother to fetus appears during birth if mother acquired the disease days before delivery. There are not many reports of confirmed chikungunya infection in newborns. Here we report a neonate infected with Chikungunya virus which was confirmed by ELISA test.

Keywords: Chikungunya virus, Fever, Neonate

\section{Amar Taksande 1, K.Y.Vilhekar}

\author{
1 MD, FIAE, Professor, Department. of \\ Pediatrics \\ $2 \mathrm{MD}, \mathrm{DCH}$, Professor \&Head, \\ Department. of Pediatrics
}

\section{Corresponding Author: Amar Taksande}

\section{amar.taksande@gmail.com}

MD, FIAE, Professor, Department. of Pediatrics, Jawaharlal Nehru Medical College, Sawangi Meghe, Wardha, Maharashtra -442102

\section{Introduction}

Chikungunya is a relatively rare form of viral fever caused by an alphavirus that is spread by mosquito bites from the Aedes aegypti mosquito. The disease was first described by Marion Robinson and W.H.R. Lumsden in 1955, following an outbreak on the Makonde Plateau, along the border between Tanganyika and Mozambique, in 1952. Symptoms appear between 4 and 7 days after the patient has been bitten by the infected mosquito. A high fever and headache occur, with significant pains in the joints (ankles, wrists) and can persist for several weeks. There are not many reports of clinical features of confirmed chikungunya infection in newborns $(1,2)$. Neonates present at 3-5 days of life with fever, excessive crying, dermatological manifestations like maculopapular rash, nasal blotchy erythema, freckle like pigmentation over centrofacial area, vesiculobullous lesions, apnea, shock, disseminated intravascular coagulation. The time of greatest risk of transmission from mother to fetus appears during birth if mother acquired the disease days before delivery. Viral chikungunya perinatally transmitted leads to encephalitis in newborn (3-5).

Gomez WV et al (6) reported that during September 2014 to February 2015, seven pregnant women with serological and reverse transcription-polymerase chain reaction-positive test for CHIK delivered eight infants with CHIK in the north of Colombia. The main preventive measure is to stop the proliferation of mosquitoes by reducing their breeding grounds. Chikungunya is a self-limiting febrile illness and responded to supportive therapy. Here, we report a cases of chikungunya infection in neonate which was confirmed by ELISA test and fully recovered with conservative management.

\section{Case Report}

A 6-day old female baby presented to us with history of fever since 3 day. No history of convulsion, rash, or bleeding from any other site. The baby was born by normal vaginal delivery at home to 24 -year old, $2^{\text {nd }}$ gravida mother at 38 -weeks of gestation. There were no history of pregnancy induced hypertension, diabetes or antenatal problems in the mother except for high grade fever with severe bodyache and headache 3-4 days before delivery. The mother was conservatively treated for fever at home. The baby cried immediately after birth and was put on the breast feeds within one hour. No prelacteal feed was given. On the $6^{\text {th }}$ day of life, baby brought to the hospital for high grade, continuous type fever along with irritability. On admission baby was excessively irritable and continuously crying. Vitals were normal. Anterior fontanelle was not bulging. Her weighed $25600 \mathrm{gm}$, length $52 \mathrm{~cm}$ and head circumference was $33 \mathrm{~cm}$. Capillary refilling time was < 3second. No hepatosplenomegaly on perabdominal examination. Cardiovascular, respiratory and neurological examination was normal. Patient was empirically started on Cefotaxime $(100 \mathrm{mg} /$ $\mathrm{kg} /$ day) and Amikacin (15mg/kg/day). Sepsis screen and blood culture was taken. In view of the chikungunya epidemic in wardha district a clinical diagnosis of chikungunya was kept in differential diagnosis.

Investigations revealed hemoglobin was $12.8 \mathrm{~g} / \mathrm{dL}$, total leukocyte count of $17,300 / \mathrm{mm}^{3}\left(4000-11000\right.$ cells/ $\mathrm{mm}^{3}$ ) with $71.3 \%$ granulocyte, $27.3 \%$ lymphocyte, $1.4 \%$ eosinophil and platelet count was 2 lac/cumm. Serum creatinine $0.7(0.6$ to $1.2 \mu \mathrm{mol} / \mathrm{L}$ ), blood urea 05 ( $3-12 \mathrm{mg} / \mathrm{dl}$ ), Sodium 138 (135 to $148 \mathrm{mmol} / \mathrm{L}$ ), Potassium 3.4 (3.5 to $5.1 \mathrm{mmol} / \mathrm{L}$ ), Serum bilirubin $4 \mathrm{mg} / \mathrm{dl}$, Alanine aminotransferase 34 ( 6-40 U/L) and Aspartate 
aminotransferase 48 ( 30-100 U/L). Blood culture was sterile and CRP was negative. Chikungunya virus specific IgM antibodies by IgM capture ELISA test were positive. In view of improved baby condition, afebrile on $2^{\text {nd }}$ day of admission and sterile blood culture, antibiotic was stopped. Baby was discharged on 10th day of life.

\section{Discussion}

Chikungunya is an RNA virus belonging to the Alphavirus genus of the Togaviridae family. It is transmitted to humans by mosquitoes of either the Aedes or Culex genus. The word chikungunya has been derived from a Makonde word meaning "that which bends up". Repeated outbreak has been observed in west, central and southern Africa and many areas of Asia. Chikungunya was first described in Tanzania, Africa in 1952. The virus first appeared in India in 1963, when along with dengue, it caused very extensive epidemic in Calcutta, Madras, and other areas. Chikungunya outbreaks occurred at irregular interval along the east coast of India and in Maharashtra till 1973. Since then the virus has been quiescent(1-3). The incubation period can be 2-12 days, but is usually 3-7 days. It can cause a debilitating illness and symptoms mainly in adult include abrupt onset of fever, chills, headache, and severe joint pain with or without swelling (usually the smaller joints), low back pain, and rash. Our case presented with fever and irritability. Unlike dengue, hemorrhagic manifestations are relatively rare and as a rule shock is not observed in chikungunya virus infection. Neonates present at 3-5 days of life with fever, excessive crying, dermatological manifestations like maculopapular rash, nasal blotchy erythema, freckle like pigmentation over centrofacial area, vesiculobullous lesions, apnea, shock, DIC. Neurological complications such as meningoencephalitis have been reported in patients during the first Indian outbreak as well as the recent French Reunion islands outbreaks (3-6).
Mother to child transmission of chikungunya virus was reported during the recent epidemic in the Reunion Island off the coast of Africa. one hundred and sixty pregnant mothers were infected with chikungunya. Of the thirty three with viremia at the time of delivery, sixteen newborns were symptomatic in the neonatal period $(7,8)$. The time of greatest risk of transmission from mother to fetus appears during birth if mother acquired the disease days before delivery. Viral chikungunya perinatally transmitted leads to encephalitis in newborn. Robillard PY et al (9) also reported that transplacental transmission of chikungunya can also occur before 16 weeks and suggest the virus played a direct role in fetal deaths. Diagnosis is made by CHIK IgM and PCR. Most often chikungunya is a self-limiting febrile illness and responded to conservative or supportive therapy $(3,9)$. The CHIMERE cohort study provides neurocognitive functions of infants infected by maternal-fetal transmission of CHIKV at birth. They found infected children exhibit poorer neurocognitive skills than uninfected peers, as evidenced by lower global developmental quotient scores and diminished specific neurocognitive skills. Thus, incidence of global neurodevelopmental delay (GND) in infected children is just over $50 \%$ but with a caveat: CHIKV encephalopathy gives the poorest neurocognitive outcome and prostration. Finally, Gérardin $P(10)$ concluded that the neurocognitive outcome of children exposed to perinatal mother-to-child CHIKV infection is poor. Severe CHIKV neonatal encephalopathy is associated with an even poorer outcome. The neurocognitive outcome of infected children is poor and must be monitored throughout childhood to anticipate the psychomotor, cognitive and behavioral therapies. The neurocognitive outcome of children exposed to perinatal mother-to-child CHIKV infection is poor. Severe CHIKV neonatal encephalopathy is associated with an even poorer outcome. In conclusion, this case report shows that viral chikungunya can be transmitted from mother to babies and clinical presentation is similar to that of septicemia or meningitis. 


\section{Refrences}

1 Jadhav M, Namboodripad M, Carman RH, Carey DE, Myers RM (1965) Chikungunya disease in infants and children in Vellore: a report of clinical and haematological features of virologically proved cases. Indian J Med Res 53: 764-776.

2 Mourya DT, Mishra AC (2006) Chikungunya fever. Lancet 368: 186-187.

3 Chikungunya Fever Fact Sheet Division of Vector-Borne Infectious Diseases, Centers for Disease Control and Prevention, Atlanta, U.S.A.

4 Lahariya C, Pradhan SK (2006) Emergence of chikungunya virus in Indian subcontinent after 32 years: A review. J Vector Borne Dis 43 : 151-160.

5 Ravi V (2006) Re-emergence of chikungunya virus in India. Indian J Med Microbiol 24: 83-84.

6 Villamil-Gómez W, Alba-Silvera L2, Menco-Ramos A3, GonzalezVergara A4, Molinares-Palacios T3, et al. (2015) Congenital
Chikungunya Virus Infection in Sincelejo, Colombia: A Case Series. J Trop Pediatr.

7 Quatresous I; Investigation Group (2006) E-alert 27 January: Chikungunya outbreak in Reunion, a French overseas department. Euro Surveill 11: E060202.

8 Lenglet Y, Barau G, Robillard PY, Randrianaivo H, Michault A, et al (2006) Chikungunya infection in pregnancy: Evidence for intrauterine infection in pregnant women and vertical transmission in the parturient. Survey of the Reunion Island outbreak. J Gynecol Obstet Biol Reprod 35: 578-583.

9 Robillard PY, Boumahni B, Gérardin P, Michault A, Fourmaintraux A, et al. (2006) [Vertical maternal fetal transmission of the chikungunya virus. Ten cases among 84 pregnant women]. Presse Med 35: 785788.

10 Gérardin P, Sampériz S, Ramful D, Boumahni B, Bintner M, et al (2014) Neurocognitive Outcome of Children Exposed to Perinatal Mother-to-Child Chikungunya Virus Infection: The CHIMERE Cohort Study on Reunion Island. PLoS Negl Trop Dis 8: e2996. 